\title{
Accessible continued professional development for maternal mental health
}

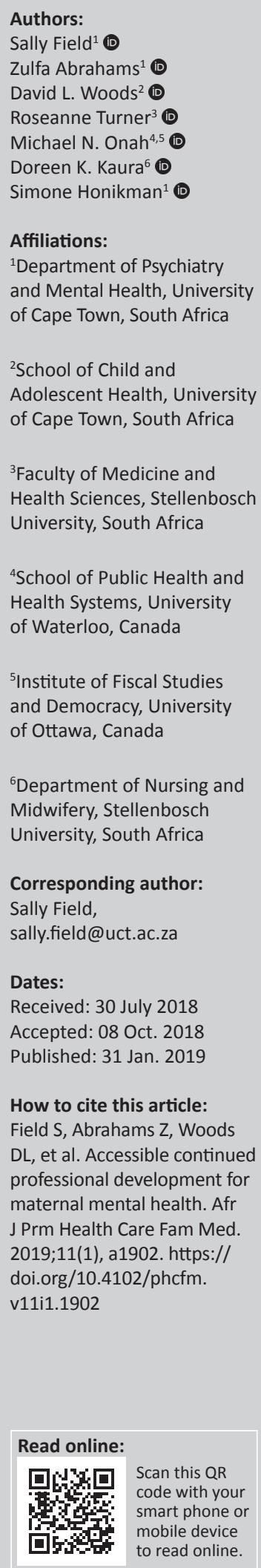

Background: Changing global health and development trends have resulted in a need for continued professional development (CPD) within the health and development sectors. In low-resource settings, where the need for training and CPD may be highest, there are significant challenges for disseminating information and skills. There is a need to improve mental health literacy and reduce levels of stigma about maternal mental illness. The Bettercare series of distance learning books provides a peer-based format for CPD. We aimed to evaluate the Bettercare Maternal Mental Health book as a format for CPD.

Aim: The aim of this study was to determine whether the Bettercare Maternal Mental Health book significantly improves knowledge and decreases stigma around mental health for care providers from the health and social development sectors.

Setting: One hundred and forty-one participants (social workers, nursing students and health professionals) were provided with the Bettercare Maternal Mental Health book to study.

Methods: Before and after studying the book, the same multiple-choice knowledge test and the Mental Illness Clinicians' Attitude Scale were used to assess cognitive knowledge and mental health stigma, respectively.

Results: Participants' knowledge showed a statistically significant $(p<0.001)$ improvement between the pre- and post-test results, for all six chapters of the book. However, participants' attitudes towards mental illness did not show a statistically significant change between the pre- and post-test results.

Conclusion: We found that this method of learning elicited significant improvement in mental health knowledge for care providers. Continued professional development policy planners and curriculum developers may be interested in these findings.

\section{Introduction}

Changing global health and development trends have resulted in a need for continued professional development (CPD) within the health and development sectors. Initial training no longer equips care providers adequately to address the changes that occur during their professional lifetime. ${ }^{1}$

Rapid medical and technological advancements challenge care providers to keep up with new trends, while the regulation of professional bodies has influenced the need for standardised practice with set curricula and thus the need for CPD in order for professionals to update their knowledge. ${ }^{2}$ Changing demographic patterns of disease have significant impacts on health delivery systems, ${ }^{1}$ resulting in the need for care providers to keep abreast with new evidence and relevant skills in order to be able to respond appropriately.

There have been several global initiatives to address the issue of CPD. More traditional forms of CPD include conferences and workshops, ${ }^{3}$ with more recent initiatives including the use of social media platforms. ${ }^{4}$ However, numerous challenges have been identified. These include juggling workload and time for study, inflexible education systems with scheduled lectures that do not take the work shift timetable into account and a gap between theory and practice. ${ }^{1}$ Further, the uptake and impact of professional development is influenced by lack of relief cover, inability to take paid study leave and an unsupportive learning culture, ${ }^{5}$ together with other constraints such as a lack of funding to support training initiatives and experienced trainers. 
In low-resource settings, where the need for training and CPD may be highest, there are even greater obstacles to disseminating information and skills. Traditional methods of continued training usually occur off-site, in urban areas, at tertiary training institutions or central teaching hospitals. For those living remotely, the expenses in terms of time, accommodation and transport are often prohibitive. ${ }^{6}$ While the use of social media and online platforms for CPD may enable care providers to remain at their place of employment while continuing their education, these options are currently inaccessible for most South Africans outside of the major metropolitan cities because of expensive data costs and lack of reliable free $\mathrm{Wi}-\mathrm{Fi}$.

In South Africa, $75 \%$ of people living with a mental disorder do not receive the care that they need. ${ }^{7}$ Common mental disorders (CMD) such as depression and anxiety are highly prevalent in low-resource settings, particularly during the perinatal period. In South Africa, perinatal CMDs are as high as $47 \%$ in rural settings ${ }^{8}$ and more than $20 \%$ in urban settings. ${ }^{9,10}$ Research has indicated the need for strengthening health systems in order to address the gap in mental healthcare delivery. This includes the need for further training of non-specialist care providers (health and social workers) at different levels. ${ }^{11}$ However, studies from South Africa report negative attitudes of care providers towards those with mental illness. ${ }^{12,13,14}$ Mavundla ${ }^{12}$ reported that $90 \%$ of nurses working in a general hospital in Durban had negative attitudes towards their mentally ill patients. As institutional stigma decreases the uptake of services by those with mental illness, ${ }^{15}$ there is thus a need to improve the mental health literacy of care providers as well as to reduce levels of stigma about mental illness.

The book Maternal Mental Health: A Guide for Health and Social Workers is one of many in the Bettercare series of distance learning books and was written by the authors of this article (SF, DW, SH). The Bettercare books provide relevant, affordable and up-to-date learning materials for care providers in under-resourced settings. The series covers a range of health topics (http://bettercare.co.za/). Each course book follows the same format: learning objectives are clearly stated at beginning of each chapter, chapter content is presented in a question-and-answer format and contains case studies that apply the chapter content to practical, real-world settings. The case studies include prompt questions for considered assessment and management options as well as model answers. Each chapter has a multiple-choice quiz consisting of 20 questions to self-assess knowledge and understanding before and after studying the chapter. The correct answers are provided at the back of the book. The first edition of the Maternal Mental Health book is divided into six chapters: 'Introduction to maternal mental health', 'Identifying maternal mental illness', 'Making referrals for maternal mental illness', 'How to help mothers with mental health problems', 'Special medical issues in maternal mental health' and 'Special social issues in maternal mental health'. The book also has a resource section with details on screening tools and accessing help for pregnancy termination, adoption, maintenance and protection orders, child support grants, as well as helplines and organisations that can assist with counselling services.

While a need to improve the mental health knowledge, understanding and attitudes of care providers has been identified, there is little agreement on strategies for training or for the evaluation of training efforts. An African systematic review on training in mental health identified key gaps for research that develops and tests innovative educational strategies, especially those that support integration of mental health systems. ${ }^{16}$ We aimed to evaluate the changes in mental health knowledge and stigma in non-specialist health and social workers using the Bettercare Maternal Mental Health book as an innovative educational strategy for distance learning CPD.

\section{Methods Study design}

This study used a pre-post-study design.

\section{Participants}

Participants for this study were recruited in one of three ways. Firstly, social workers who enrolled for training in maternal mental health through a Western Cape Department of Social Development CPD programme were requested to participate in the study prior to attending a workshop - there were 59 participants recruited in this manner, with no refusals to participate. Secondly, basic and advanced midwifery students from the University of Stellenbosch were asked to participate in the study as part of their coursework - there were 55 participants from this group, with no one declining to participate. The remaining 27 participants were health or social worker students and professionals who had accessed the Maternal Mental Health book online and volunteered to participate in the study.

\section{Procedure}

All participants were provided with a copy of Bettercare Maternal Mental Health, free of charge. The study process was clearly explained, either in person by a facilitator or online, in written form. Participants were encouraged to form small study groups, ideally of about five people, and to work their way through the course book, chapter by chapter, discussing the concepts and case studies. Participants were required to keep an attendance register that documented attendance, dates of group meetings and the chapters that were studied at each session. Individuals who participated in the study outside of the group format were not required to document their study times.

\section{Data collection}

A self-administered questionnaire was used to collect sociodemographic information from participants at the beginning 
of the study. The Mental Illness Clinicians' Attitude Scale (MICA-4) was used to assess participants' stigma towards people with mental illness ${ }^{17}$ before and after participating in the study of the Maternal Mental Health book. The MICA-4 version was designed to assess health and social care professionals' attitudes, views and knowledge. It consists of 16 questions with a six-point Likert scale, which was completed as a self-administered survey. The lowest possible score on the scale is 16 , and the highest 96 . Ten of the items are reverse scored. A high overall score is an indication of a more negative (stigmatising) attitude. It has been used in other African settings ${ }^{18}$ and in South Africa with nurses in primary care clinics. ${ }^{19}$

Before participating in the self-study process, participants completed a multiple-choice test consisting of 75 questions. These were devised by the authors of the book and were peer-reviewed. The questions related to the content of the six chapters of the book. The same multiple-choice test was repeated after completion of the book, several weeks later. The results of the pretest indicated the participants' knowledge of the subject matter before studying the material, while the post-test indicated their knowledge after studying it. The difference between the two results indicated the amount of knowledge gained in the interval.

To assess the perceived usefulness of the process, we asked participants about the difficulties they had experienced, as well as what aspects and sections of the content they found to be particularly helpful.

\section{Data analysis}

Data analysis was performed using Stata/SE statistical software package version 14.0 (StataCorp, College Station, TX, Unites States of America [US]). Because the data were not normally distributed, the stigma and knowledge scores were described as medians with interquartile ranges and were compared using the Wilcoxon signed-rank test for paired samples. Participants' comments on the difficulties they experienced and the most helpful areas of the book were analysed using simple thematic analysis.

\section{Ethical consideration}

The study proposal was approved by the Research Ethics Committee of the Faculty of Health Sciences at the University of Cape Town (Ref. 474/2015) and from the University of Stellenbosch Health Research Ethics Committee (Ref. N15/10/105). Written informed consent was obtained from all participants prior to participation in the study.

\section{Results}

The demographic characteristics of the 141 participants who completed the pre- and post-tests are shown in Table 1. The majority were aged between 26 and 35 years (43\%) and were women (95\%) working in South Africa (95\%). Almost half the sample (47\%) were social workers or social work assistants, while $37 \%$ were nurses. The remaining
TABLE 1: Demographic characteristics of participants $(n=141)$

\begin{tabular}{|c|c|c|}
\hline \multirow[t]{2}{*}{ Variable } & \multicolumn{2}{|c|}{ Participants } \\
\hline & $n$ & $\%$ \\
\hline \multicolumn{3}{|l|}{ Age } \\
\hline$<25$ years & 20 & 12.2 \\
\hline $26-35$ years & 60 & 42.6 \\
\hline $36-45$ years & 31 & 22.0 \\
\hline$>46$ years & 30 & 21.3 \\
\hline \multicolumn{3}{|l|}{ Gender } \\
\hline Men & 7 & 4.9 \\
\hline Women & 134 & 95.0 \\
\hline \multicolumn{3}{|l|}{ Country of residence } \\
\hline South Africa & 118 & 92.9 \\
\hline Other & 10 & 5.7 \\
\hline \multicolumn{3}{|l|}{ Employment status } \\
\hline Employed & 118 & 83.7 \\
\hline Unemployed & 9 & 7.1 \\
\hline \multicolumn{3}{|l|}{ Location of residence } \\
\hline Rural & 23 & 18.1 \\
\hline Urban & 104 & 81.9 \\
\hline \multicolumn{3}{|l|}{ Type of job } \\
\hline Nurse (professional/specialised/midwife/enrolled) & 46 & 36.8 \\
\hline Social worker/social work assistant & 59 & 47.2 \\
\hline Unspecified other & 20 & 16.0 \\
\hline \multicolumn{3}{|l|}{ Type of mental health training received } \\
\hline None & 82 & 58.2 \\
\hline Degree & 32 & 22.7 \\
\hline Workshop/seminar & 11 & 7.8 \\
\hline Informal & 13 & 9.2 \\
\hline \multicolumn{3}{|l|}{ Study method used } \\
\hline In a group & 102 & 72.3 \\
\hline Individually & 39 & 27.7 \\
\hline
\end{tabular}

participants were registered professionals from the health or social development sectors and included doctors and a psychologist. More than half (58\%) reported no previous mental health training. Not all demographic information was provided by all participants.

Participants' knowledge showed a statistically significant $(p<0.001)$ improvement (Table 2$)$ between the pre- and posttest results, for all six chapters, irrespective of the method of recruitment. Only two participants failed to get a post-study score of $80 \%$ or above.

Most subgroups (Table 3) showed statistically significant $(p<0.001)$ improvement in knowledge between the preand post-test. The exception was those who had received previous mental health training at a workshop or seminar $(p=0.111)$. The poorest median knowledge scores at baseline were for those who were $36-45$ years old $(57 / 75)$, men $(57 / 75)$ and those who completed the programme on their own (57/75). Subgroups with the highest median knowledge scores at the post-test included men (73/75) and those who had received previous training at a workshop or seminar $(74 / 75)$.

Overall, the participants' attitudes towards people with a mental illness did not show a statistically significant change between the pre- and post-test results $(p=0.486)$ (Table 4$)$. The median score was 38 for the pretest, which decreased to 37 at the post-test. 
TABLE 2: Comparison of pre- and post-test scores for chapters in the maternal mental health course book $(n=141)$.



IQR, interquartile range.

$*$, Paired $t$-test.

TABLE 3: Comparison of pre- and post-test knowledge scores (maximum possible score $=75$ ).

\begin{tabular}{|c|c|c|c|c|c|}
\hline \multirow[t]{2}{*}{ Variable } & \multicolumn{2}{|c|}{ Pretest score } & \multicolumn{2}{|c|}{ Post-test score } & \multirow[t]{2}{*}{$p$-value* } \\
\hline & Median & IQR & Median & IQR & \\
\hline \multicolumn{6}{|l|}{ Age } \\
\hline$<25$ years & 65 & $63-68$ & 72 & $68-74$ & 0.005 \\
\hline $26-35$ years & 60 & $56-65$ & 72 & $70-73$ & $<0.001$ \\
\hline $36-45$ years & 57 & $52-66$ & 72 & $67-74$ & $<0.001$ \\
\hline$>46$ years & 61 & $53-64$ & 70 & $67-73$ & $<0.001$ \\
\hline Men & 57 & $55-65$ & 73 & $64-74$ & 0.013 \\
\hline Women & 61 & $55-65$ & 71 & $69-73$ & $<0.001$ \\
\hline \multicolumn{6}{|l|}{ Country of employment } \\
\hline South Africa & 60 & $55-65$ & 72 & $68-73$ & $<0.001$ \\
\hline Other & 64 & $56-69$ & 71 & $69-73$ & 0.009 \\
\hline \multicolumn{6}{|l|}{ Location of employment } \\
\hline Rural & 63 & $56-66$ & 71 & $67-73$ & $<0.001$ \\
\hline \multicolumn{6}{|l|}{ Type of job } \\
\hline Nurse (professional/specialised/ midwife/enrolled) & 59 & $53-62$ & 71 & $67-73$ & $<0.001$ \\
\hline Social worker/social worker assistant & 63 & $57-66$ & 72 & $70-73$ & $<0.001$ \\
\hline Unspecified other & 65 & $61-69$ & 71 & $65-74$ & 0.034 \\
\hline \multicolumn{6}{|l|}{ Type of mental health training received } \\
\hline None & 58 & $53-63$ & 72 & $69-73$ & $<0.001$ \\
\hline Degree & 64 & $60-67$ & 71 & $68-73$ & $<0.001$ \\
\hline Workshop/seminar & 65 & $58-66$ & 74 & $64-75$ & 0.111 \\
\hline Informal & 61 & $59-65$ & 72 & $67-73$ & 0.018 \\
\hline \multicolumn{6}{|l|}{ Study method used } \\
\hline In a group & 61 & $56-66$ & 71 & $68-73$ & $<0.001$ \\
\hline Individually & 57 & $51-66$ & 72 & $70-73$ & $<0.001$ \\
\hline Total score & 61 & $55-66$ & 71 & $69-73$ & $<0.001$ \\
\hline
\end{tabular}

IQR, interquartile range.

*, Paired $t$-test.

There was no significant difference in change of knowledge score $(p=0.083)$ or change in stigma score $(p=0.964)$ for those who studied individually compared to those who participated in group study sessions.

When asked about areas that were difficult to understand in the book, the majority of participants (78\%) reported having no difficulties. With regard to the content of the Maternal Mental Health book, eight participants indicated that they found the scoring of one of the screening tools difficult to understand, with six indicating that the screening tools were particularly helpful. Two social worker participants reported some difficulty in understanding some of the medical terminology.
Participants reported that the book contained 'well-structured chapters', 'short paragraphs that were easy to read' and 'manageable segments of information' and that the book was 'easy to understand'.

The most helpful reported areas of the book included the management of mentally ill patients $(27 \%)$, the entire book $(26 \%)$, case studies $(10 \%)$ and the resource section $(10 \%)$.

Further, $14 \%$ of the participants provided examples of how they could apply their knowledge in their personal or work lives. Many participants reported being better equipped to identify and treat women with a mental illness. 
TABLE 4: Comparison of pre- and post-test stigma scores on the Mental Illness Clinicians' Attitude scale $(n=136) \dagger$.

\begin{tabular}{|c|c|c|c|c|c|}
\hline \multirow[t]{2}{*}{ Variable } & \multicolumn{2}{|c|}{ Pretest stigma score } & \multicolumn{2}{|c|}{ Post-test stigma score } & \multirow[t]{2}{*}{$p$-value* } \\
\hline & Median & IQR & Median & IQR & \\
\hline \multicolumn{6}{|l|}{ Age } \\
\hline$<25$ years & 40 & $37-45$ & 36 & $28-48$ & 0.179 \\
\hline $26-35$ years & 37 & $32-42$ & 40 & $30-43$ & 0.528 \\
\hline $36-45$ years & 39 & $34-44$ & 38 & $34-40$ & 0.955 \\
\hline$>46$ years & 37 & $29-43$ & 35 & $28-42$ & 0.358 \\
\hline \multicolumn{6}{|l|}{ Gender } \\
\hline Men & 42 & $32-47$ & 37 & $28-43$ & 0.028 \\
\hline Women & 37 & $32-42$ & 37 & $30-42$ & 0.636 \\
\hline \multicolumn{6}{|l|}{ Country of employment } \\
\hline South Africa & 38 & $33-42$ & 37 & $29-42$ & 0.259 \\
\hline Other & 37 & $27-45$ & 37 & $33-47$ & 0.533 \\
\hline \multicolumn{6}{|l|}{ Location of employment } \\
\hline Rural & 40 & $34-44$ & 40 & $34-44$ & 0.855 \\
\hline \multicolumn{6}{|l|}{ Type of job } \\
\hline Nurse (professional/specialised/ midwife/enrolled) & 37 & $33-40$ & 37 & $28-41$ & 0.582 \\
\hline Social worker/social worker assistant & 38 & $31-42$ & 37 & $30-43$ & 0.502 \\
\hline Unspecified other & 36 & $30-47$ & 40 & $35-43$ & 0.654 \\
\hline \multicolumn{6}{|l|}{ Type of mental health training received } \\
\hline None & 39 & $34-44$ & 38 & $30-41$ & 0.033 \\
\hline Degree & 35 & $31-41$ & 37 & $30-47$ & 0.594 \\
\hline Workshop/seminar & 32 & $26-37$ & 37 & $32-43$ & 0.169 \\
\hline Informal & 37 & $32-39$ & 40 & $27-47$ & 0.916 \\
\hline \multicolumn{6}{|l|}{ Study method used } \\
\hline In a group & 38 & $32-42$ & 38 & $30-43$ & 0.553 \\
\hline Individually & 38 & $33-45$ & 37 & $27-42$ & 0.700 \\
\hline Overall score & $38 *$ & $32-43$ & 37 & $30-42$ & 0.486 \\
\hline
\end{tabular}

$I Q R$, interquartile range.

*, Paired Wilcoxon signed-rank test.

$\dagger$, Five participants had incomplete questionnaires and therefore needed to be excluded from this sample.

$\$$, A high overall score indicates a more negative (stigmatising) attitude.

Others commented on their increased understanding and feelings of empathy for pregnant women with mental illnesses.

\section{Discussion}

This study evaluated the Bettercare Maternal Mental Health book as a distance learning format. We found that this method of learning elicited significant improvement in maternal mental health knowledge for care providers in the health and social development sectors but was not effective at changing participants' attitudes towards mental illness. The majority of participants reported that the chapters were well structured and easy to understand.

In a review of over 100 trials concerning continued professional education activities, Oxman et al. concluded that dissemination-only strategies, such as conferences or mailing of unsolicited information, may assist with providing new knowledge but demonstrated little change in professional behaviour. ${ }^{20}$ Educational scholars have argued that more complex cognitive processes are needed for putting knowledge into practice. These would include knowledge comprehension, application, analysis, synthesis and evaluation. ${ }^{3}$

The Bettercare method of using questions and answers followed by case studies attempts to integrate some of these more complex processes into learning, moving beyond knowledge comprehension. Participants are encouraged to apply the knowledge content by working through a series of real-life case study scenarios, analysing the information and then evaluating their change in knowledge through before and after quizzes. Peer group discussions encourage participants to engage actively with the material and assist each other with assimilating new knowledge. It is therefore not surprising that participants' knowledge improved significantly between the pre- and post-test. Feedback on the content of the Maternal Mental Health book further demonstrates participants' perception of their improved ability to apply their improved knowledge of maternal mental health in their personal and work environments. These findings concur with previous studies by Woods and Theron that this format of decentralised learning increases cognitive knowledge. ${ }^{21}$ Theron demonstrated significant change in knowledge among midwives who studied the Maternal Care book $^{22}$ and Woods demonstrated similar success in his study that showed improved cognitive knowledge of Neonatal Care by neonatal nurses in a district hospital and satellite clinic. ${ }^{23}$ These studies drew on participants from both rural and urban areas from all levels of the health system.

In a prospective controlled trial, Theron found that the change in cognitive knowledge about maternal care also resulted in a change in participants' attitudes towards 
their work. ${ }^{24}$ The midwives in his study reported that improved cognitive knowledge and ability to apply this knowledge was also personally experienced, resulting in an increase in job satisfaction and self-confidence. We did not measure these items. Rather, we looked at stigma around mental health as the important attitude being influenced by the process of engaging with the content of the book. We found that while participants' attitudes towards mental illness did not change significantly, their stigma scores were reduced.

Greater mean scores on the MICA scale indicate higher levels of stigma towards mental health. The mean score in this study prior to the learning process was far lower than the mean scores for similar professionals and medical students who underwent training in identifying mental health disorders in China. ${ }^{25,26}$ In both these studies, the pre-and post-mean MICA scores ranged between 47 and 41. A Nigerian study used the MICA to assess university staff attitudes towards mental illness. Across all university faculties, the mean total scores ranged between 44 and 80 , with faculty members from the psychiatry department scoring the lowest mean score of $44 .{ }^{18}$ The pretest MICA mean score for our study was 38 and the post-test had a nonsignificant lowered mean score of 37 . This seems to suggest that even prior to completing the Maternal Mental Health book, our participants were less prejudiced about mental health issues than their contemporaries in China or Nigeria and had similar attitude scores to midwives in a study from Ireland (mean score of 36$)^{27}$ and medical students at an English university (mean score of 34 ). ${ }^{17}$ We are unable to compare the scores to a South African study who surveyed primary care nurses, as a different scoring system was used. However, that study reported a 'relatively positive attitude towards mental illness' by primary care nurses. ${ }^{19}$

Studies reporting effective methods for reducing stigma seem to be limited, however, pilot interventions where participants have contact with those living with mental illness seem to be promising. ${ }^{28}$ Experiential learning, rather than paper-based study, may be necessary for changing negative attitudes towards mental illness. A review on interventions that have been successful in changing knowledge and attitudes towards mental illness indicates that personal experience and a focus on modelling skills and behaviour have been most effective. ${ }^{29}$ While the Maternal Mental Health book provides case studies to apply knowledge and model typical scenarios pertaining to maternal mental illness, this does not seem to be sufficient for significant changes in attitude. Some of the authors of this article, through the Perinatal Mental Health Project, have recently developed a short film to model empathic engagement (http://bit.ly/PMHP_ESS), aimed to supplement the book in providing visual demonstration of the skills.

An Australian study, looking at CPD in rural areas, found that professional isolation was one of the factors that stimulated the need for CPD activities. ${ }^{30}$ The peer group learning format encouraged by Bettercare addresses this. Participants are encouraged to learn in small groups, motivating each other and sharing knowledge in a collaborative way. The selfdirected learning approach enables participants to study at flexible times and at their own pace. A formal tutor is not needed for this method of cooperative learning and peer tuition, although a facilitator is helpful.

While we did not find a significant difference in either change in knowledge or change in mental health stigma between those who studied individually compared to those who studied in a group setting, this could have been influenced by the method of recruiting participants into the study. More participants who studied the book as individuals self-selected to participate via online recruitment and thus may have been more motivated to engage with the content of the study.

\section{Limitations}

The study is limited in that it has a relatively small sample size. While this study assessed knowledge and attitudes, it was not designed to examine how these were applied as skills and work performance. Further, we did not measure the long-term retention of knowledge.

Further, pre-and post-test design may be subject to a number of confounding variables such as maturation, history, test effect and the regression to the mean effect. ${ }^{31}$ These are noteworthy limitations when there is no comparison group against which to evaluate the findings.

We acknowledge that some of the authors of the Maternal Mental Health book are also the researchers in this study. While this may be a source of bias, effort was taken to limit this through use of other researchers for data collection and analysis, who were not directly linked to the development or the outcomes of the book.

Although pragmatic constraints in the recruitment process led to a large majority of urban participants, we anticipate the benefits of the Maternal Mental Health book would be equally felt for rural user groups. In particular, these populations may best be served by the online open access platform of the Bettercare series.

\section{Conclusion}

Despite these limitations, the findings suggest that the Bettercare format could be an effective method for CPD and that the Maternal Mental Health book improves knowledge among different provider cadres who do not typically integrate mental healthcare in their routine practice. These findings may be of interest to those involved in the policy, planning and implementation of curricula for training and CPD for care providers in the health and social development sectors, particularly in regions where there is a high prevalence of maternal mental ill health and low levels of human resources to meet this need. Future research should seek to measure the application of mental health knowledge and skills in the workplace, as well as long-term retention 
of these. In particular, there is scope to research whether and how video training materials impact practice, particularly in the field of mental health.

\section{Acknowledgements Competing interests}

The authors declare that they have no financial or personal relationships that may have inappropriately influenced them in writing this article.

\section{Authors' contributions}

S.F., R.T., D.L.W., M.N.O. and S.H. contributed to the study design. R.T., M.N.O. and D.K.K. assisted with participant recruitment and data collection. S.F. and R.T. were responsible for the data management. Z.A. analysed the data. S.F. drafted the initial manuscript. All authors reviewed and contributed to the final manuscript.

\section{Funding information}

The study was supported by the Harry Crossley Foundation.

\section{References}

1. Clark E, Draper J, Rogers J. Illuminating the process: Evaluating the impact of continuing professional education on practice. Nurse Educ Today. 2015;35(2): 388-394. https://doi.org/10.1016/j.nedt.2014.10.014

2. Beddoe L. Continuing education, registration and professional identity in New Zealand social work. Int Soc Work. 2015:58(1):165-174. https://doi.org/10.1177/ 0020872812473139

3. Légaré $F$, Freitas $A$, Thompson-Leduc $P$, et al. The majority of accredited continuing professional development activities do not target clinical behaviour change. Acad Med [serial online]. 2015[cited 2016 Oct 03];90(2):197-202. Available from: http://content.wkhealth.com/linkback/openurl?sid=WKPTLP:landingpage\& an=00001888-201502000-00025

4. Moorley C, Chinn T. Using social media for continuous professional development J Adv Nurs. 2015;71(4):713-717.

5. Coventry TH, Maslin-prothero SE, Smith G. Organizational impact of nurse supply and workload on nurses continuing professional development opportunities: An integrative review. J Adv Nurs. 2015;71(12):2715-2727. https://doi.org/10.1111/ jan.12724

6. Woods D, Cope F, Eley B. The challenge of providing HIV training to health professionals. South Afr J HIV Med. 2008;9(3):15-17.

7. Mathers $C D$, Loncar D. Projections of global mortality and burden of disease from 2002 to 2030. PLoS Med [serial online]. 2006 [cited 2014 May 24];3(11):e442. Available from: http://www.pubmedcentral.nih.gov/articlerender.fcgi?artid=166 4601\&tool=pmcentrez\&rendertype=abstract

8. Rochat TJ, Tomlinson M, Newell M-L, Stein A. Detection of antenatal depression in rural HIV-affected populations with short and ultrashort versions of the Edinburgh Postnatal Depression Scale (EPDS). Arch Womens Ment Health [serial online]. 2013 [cited 2014 Jun 26];16(5):401-410. Available from: http://www. pubmedcentral.nih.gov/articlerender.fcgi?artid $=3778840 \&$ tool $=$ pmcentrez\&rend ertype=abstract

9. van Heyningen $T$, Honikman $S$, Myer L, Onah MN, Field $S$, Tomlinson M. Prevalence and predictors of anxiety disorders amongst low-income pregnant women in urban South Africa: A cross-sectional study. Arch Womens Ment Health. 2017;20(6):765-775.
10. Heyningen T Van, Myer L, Onah M, Tomlinson M, Field S, Honikman S. Antenatal depression and adversity in urban South Africa. J Affect Disord. 2016;203:121-129. Available from: https://doi.org/10.1016/j.jad.2016.05.052

11. Shidhaye R, Lund C, Chisholm D. Closing the treatment gap for mental, neurological and substance use disorders by strengthening existing health care platforms: Strategies for delivery and integration of evidence - Based interventions. IJMHS, BioMed Central. 2015;9:1-11. https://doi.org/10.1186/s13033-015-0031-9

12. Mavundla TR, Uys LR. The attitudes of nurses towards mental ill people in a general hospital setting in Durban. Curationi. 1997;20(2):3-7. https://doi.org/ 10.4102/curationis.v20i2.1297

13. Mavundla TR. Professional nurses' experience of violence when nursing mentally ill people in general hospital settings. J Adv Nurs. 2000;32(6):1569-1578. https:// doi.org/10.1046/j.1365-2648.2000.01661.x

14. Lethoba K, Netswera F, Rankhumise E. How professional nurses in general hospital setting perceive mentally ill patients. Curationis. 2006;29(4):4-11.

15. Kakuma R, Kleintjes S, Lund C, Drew N, Green A, Flisher AJ. Mental health stigma: What is being done to raise awareness and reduce stigma in South Africa?. Afr Psychiatry [serial online]. 2010 [cited 2016 Oct 03];13(2):116-124. Available from: http://www.ncbi.nlm.nih.gov/pubmed/20473472

16. Liu G, Jack H, Piette A, et al. Mental health training for health workers in Africa: A systematic review. Lancet Psychiatry. 2016;3:65-76.

17. Gabbidon J, Clement S, van Nieuwenhuizen A, et al. Mental illness: Clinicians' Attitudes (MICA) scale-psychometric properties of a version for healthcare students and professionals. Psychiatry Res. 2013;206(1):81-87. https://doi.org/ 10.1016/j.psychres.2012.09.028

18. Sheikh TL, Adekeye O, Olisah Vo, Mohammed A. Stigmatisation of mental illness among employees of a Northern Nigerian University. Niger Med J. 2015;56(4): 244-248. https://doi.org/10.4103/0300-1652.169697

19. Dube FN, Uys LR. Integrating mental health care services in primary health care clinics: A survey of primary health care nurses' knowledge, attitudes and beliefs. S Afr Fam Pract. 2016;58(3):119-125. https://doi.org/10.1080/20786190.2016. 1191747

20. Oxman AD, Thomson MA, Davis DA, Haynes B. No magic bullets: A systematic review of 102 trials of interventions to improve professional practice. Can Med Assoc J. 1995;153(10):1423-1431.

21. Woods DL, Theron GB. The impact of the perinatal education programme on cognitive knowledge in midwives. J Midwife Obstet Units. 1995;85(3):3-6.

22. Theron GB. Improved cognitive knowledge of midwives practising in the Eastern Cape Province of the Republic of South Africa through the study of a selfeducation manual. Midwifery. 1999;15:66-71. https://doi.org/10.1080/2078619 0.2016 .1191747

23. Woods DL, Greenfield DH. Teaching neonatal care in under-resourced hospitals: Experience from South Africa. Neoreviews. 2010;11:5-11. https://doi.org/10.1542/ neo.11-1-e5

24. Theron GB. The effect of the maternal care manual of the perinatal education programme on the attitude of midwives towards their work. Curationis. 1999:22:63-68. https://doi.org/10.4102/curationis.v22i4.763

25. Li J, Li J, Huang $Y$, Thornicroft G. Mental health training program for community mental health staff in Guangzhou, China: Effects on knowledge of mental illnes and stigma. Int J Ment Health Syst. 2014;8:4-9. https://doi.org/10.1186/1752 4458-8-49

26. Rong Y, Glozier N, Luscombe GM, Davenport TA, Huang Y, Hickie IB. Improving knowledge and attitudes towards depression: A controlled trial among Chinese medical students. BMC Psychiatry. 2011;11(1):36. https://doi.org/10.1186/1471 244X-11-36

27. Noonan M, Jomeen J, Galvin R, Doody O. Survey of midwives' perinatal mental health knowledge, confidence, attitudes and learning needs. Women Birth. 2018;31(6):358-366. https://doi.org/10.1016/j.wombi.2018.02.002

28. Pinto-foltz MD, Logsdon MC. Reducing stigma related to mental disorders: Initiatives, interventions, and recommendations for nursing. Arch Psychiatr Nurs. 2009;23(1):32-40. https://doi.org/10.1016/j.apnu.2008.02.010

29. Gronholm PC, Henderson C, Deb T, Thornicroft G. Interventions to reduce discrimination and stigma: The state of the art. Soc Psychiatry Psychiatr Epidemiol. 2017;52(3):249-258. https://doi.org/10.1007/s00127-017-1341-9

30. Mclean R. Continuing professional development for rural physicians: An oxymoron or just non-existent?. Clin Perspect. 2006;36:661-664. https://doi.org/10.1111/ j.1445-5994.2006.01173.x

31. Marsden E, Torgerson CJ. Single group, pre- and post-test research designs: Some methodological concerns. Oxford Rev Educ. 2012;38(5):583-616. https://doi.org/ 10.1080/03054985.2012.731208 